\title{
Advanced Stages of Chronic Venous Disease: Evolution of Surgical Techniques and Advantages of Associated Medical Treatment
}

Fedor Lurie

Received: November 26, 2019 / Published online: January 24, 2020

(c) The Author(s) 2020

\section{ABSTRACT}

Contemporary interventional treatment of primary chronic venous disease (CVD) is mainly focused on the treatment of venous reflux. The long-term results of endovenous ablation (EVA) and high ligation and stripping are not different with respect to varicose vein recurrence, and this recurrence appears to be a manifestation of disease progression. Since inflammation is one of the key mechanisms of CVD development and progression, efforts to minimize inflammation and angiogenic potential in endovenous and surgical procedures are worthwhile. As techniques continue to be refined, surgery remains a valid option; in particular, the techniques that minimize trauma can be beneficial regarding recurrence. Medical treatment with venoactive drug therapy such as micronized purified flavonoid fraction (MPFF; Daflon ${ }^{\circledR}$ ), which has proven clinical benefits in patients

Enhanced Digital Features To view enhanced digital features for this article go to https://doi.org/10.6084/ m9.figshare.11417586.

F. Lurie $(\square)$

Jobst Vascular Institute, Toledo, OH, USA

e-mail: fedor.lurie@promedica.org with CVD, can be used before and after EVA or surgery to minimize inflammation, pain, hemorrhage, and reduce CVD symptoms.

Keywords: Chronic venous disease; Chronic venous insufficiency; Endovenous laser ablation; Greater saphenous vein; Micronized purified flavonoid fraction 


\section{Key Summary Points}

Contemporary interventional treatment of primary chronic venous disease (CVD) is mainly focused on the treatment of venous reflux

The long-term results of endovenous ablation (EVA) and high ligation and stripping (HLS) are not different with respect to varicose vein recurrence, and this recurrence appears to be a manifestation of disease progression

Since the inflammation is one of the key mechanisms of CVD development and progression, efforts to minimize inflammation and angiogenic potential in endovenous and surgical procedures are worthwhile

As techniques continue to be refined, surgery remains a valid option; in particular, the techniques that minimize trauma can be beneficial with respect to recurrence

Medical treatment with venoactive drug therapy such as micronized purified flavonoid fraction (MPFF; Daflon ${ }^{\circledR}$ ), which has proven clinical benefits in patients with CVD, can be used before and after EVA or surgery to minimize inflammation, pain, hemorrhage, and reduce CVD symptoms

\section{INTRODUCTION}

Contemporary interventional treatment of primary chronic venous disease (CVD) is mainly focused on the treatment of venous reflux. Early medical investigations revealed anatomical and hemodynamic connections between saphenous vein reflux and varicose veins, and led to the notion that varicose veins could be treated by eliminating reflux through high ligation of the greater saphenous vein (GSV). However, with time it became clear that high ligation of the GSV alone was insufficient and did not change the course of the disease. The addition of surgical ablation or stripping of the saphenous veins provided better outcomes and reduced varicose vein recurrence. Yet even these measures proved to be imperfect because varicose vein recurrences remained a problem. These recurrences were considered to be mainly a result of the errors in surgical technique, such as leaving a long saphenous stump or not ligating groin tributaries. In addition, surgical trauma to the limb was considered to be a possible factor in neovascularization.

In 1999, the advent of outpatient endovascular treatments such as endovenous laser ablation (EVLA) and radiofrequency ablation (RFA) was considered to be a tremendous improvement, at least initially. Numerous clinical trials in the 2000s showed that endovenous ablation (EVA) was as effective as the high ligation and stripping (HLS) techniques used at that time and caused much less pain and trauma to the patients, allowing them to recover and return to normal activities and work more quickly, sometimes immediately. These advantages and financial benefits of EVA increased the popularity of these procedures. However, EVA procedures were also found to be wanting because recurrence and neovascularization rates were similar to those with HLS. Over time, it has become clear that the chief benefits of EVA lie in the improved perioperative patient experience and in the marginal reduction in healthcare costs, not in the longterm efficacy in preventing varicose vein recurrence $[1,2]$. This article is based on previously conducted studies and does not contain any studies with human participants or animals performed by the author.

\section{TECHNICAL IMPROVEMENTS TO ENDOVENOUS AND SURGICAL PROCEDURES}

Routine use of ultrasound is one of the major factors contributing to the success of endovascular techniques by increasing anatomical precision. However, the anatomy of the 
saphenofemoral junction (SFJ) has been shown to be quite heterogeneous with vein duplications, bifid junctions, or ectasia present in over $10 \%$ of individuals [3]. These findings indicate that ultrasound assessments should be performed prior to a surgical or EVA procedure and suggest that HLS, if performed correctly, may be more efficient than EVA at removing different anatomical variants of the SFJ. Indeed, the use of ultrasound guidance and tumescent anesthesia in contemporary HLS has improved the short-term outcomes and perioperative experience of HLS [4-6]. Although these technical improvements were developed around the same time as EVA, all clinical trials comparing the two modalities used classic HLS techniques, and no clinical trials have yet compared EVA to contemporary HLS [1, 7-9].

In a recent meta-analysis comparing longterm outcomes of EVLA and HLS, recanalization rates tended to be higher with EVLA, but neovascularization rates were higher with HLS [1]. The end result was that these negative trends canceled the advantages of each technique, so that the overall rates of recurrence were similar for both methods. There was, however, a slight but non-significant trend for less reintervention with HLS. In another systematic review and meta-analysis comparing these methods in studies with follow-ups of at least 2 years, the authors found only minor differences in the sites of recurrence but, again, EVA suffered from higher rates of recanalization and HLS from higher rates of neovascularization, with overall recurrence rates similar for both techniques [2]. The consistent finding that recurrence is similar regardless of the type of intervention used strongly suggests that both methods may slow progression, but they are unable to prevent it over time.

The question of whether removal of GSV tributary veins is necessary to prevent recurrence was also recently addressed [10]. Patients had high ligation either alone or with ligation of SFJ tributaries. Surprisingly, ligation of the tributaries was associated with a higher risk of recurrence.

\section{INFLAMMATION IN VENOUS DISEASE AND AFTER VEIN PROCEDURES}

It is well known that inflammation plays a central role in the development and progression of CVD. Among other pathological processes, inflammation precedes and causes the development of changes in the venous wall and valve resulting in reflux. When valves become incompetent, abnormal venous hemodynamics increase inflammation and close a feed-forward cycle of venous wall remodeling and dysfunction, which is a pathological hallmark of CVD and chronic venous insufficiency (CVI) $[11,12]$. In addition to tissue inflammation in the limbs of patients with CVD, the inflammatory response to any interventions (open or endovascular) can be linked to the treatment outcomes. Taengsakul et al. examined inflammation associated with endovenous RFA and HLS and found that post-procedural concentrations of the inflammatory markers interleukin-6 and C-reactive protein were elevated after both methods, but the increases were significantly lower with RFA than with HLS [13]. These changes also correlated with post-procedural pain, which was significantly less intense with RFA than with HLS.

The possibility that venoactive drug (VAD) therapy with micronized purified flavonoid fraction (MPFF; Daflon ${ }^{\circledR}$ ), which has been shown to provide a number of benefits to patients with CVD, could also benefit patients undergoing an endovenous or HLS procedure has been investigated in several clinical trials. One such study examined the effects of MPFF treatment $(1000 \mathrm{mg} /$ day for 14 days before and 14 days after stripping) on postoperative pain in patients undergoing a vein stripping procedure $[14,15]$. At each day during the 8 days after the stripping procedure, there were more pain-free patients in the MPFF treatment group $(N=92)$ than in the untreated control group $(N=89)$. This benefit was also reflected in the number of patients requiring analgesics, which was significantly lower in the MPFF treatment group (3.3\%) than in the control group $(12.5 \%)$ by postoperative day $4(P=0.023)$. In addition, 
postoperative quality of life (QoL) was assessed using the Chronic Venous Insufficiency Quality of Life Questionnaire (CIVIQ) which is a disease-specific instrument to measure the impact of CVI on patients' lives. This questionnaire measures physical, psychological, and social impairment, as well as pain due to CVI. The CIVIQ scores indicated that pain-related QoL improved to a greater extent in the MPFF group. In another study, the same MPFF treatment regimen was used in patients undergoing GSV stripping $[16,17]$. Postoperative pain and hematoma were significantly less in the MPFF treatment group than in the untreated control group at 7,14 , and 30 days after surgery. These observations are consistent with the known anti-inflammatory effects of MPFF and suggest that MPFF treatment can reduce pain and inflammation due to surgical stripping of varicose veins.

\section{INFLAMMATION AS A PRECURSOR TO NEOVASCULARIZATION}

Tissue injury triggers inflammatory responses known to promote angiogenesis through hypoxia, leukocyte and endothelial cell activation, and the activation or release of multiple mediators such as hypoxia-inducible factor, NF$\kappa \mathrm{B}$, and vascular endothelial growth factor. In the context of EVA and HLS, activation of such angiogenic inflammatory pathways may lead to revascularization and varicose vein recurrence. Indeed, molecular markers of apoptosis and vein wall necrosis such as p53 and caspase, both of which participate in angiogenesis, have been detected in histopathologic analyses of isolated veins subjected to in vitro endovenous laser ablation treatments at different energy densities [18]. In these experiments, the levels of these apoptotic markers correlated with the energy intensity of treatment, suggesting that energy levels might be optimized to allow efficient ablation without excessive induction of inflammatory and/or angiogenic pathways.

Such findings may be extrapolated to vein surgical techniques as well, suggesting that minimizing postoperative inflammation could be an important goal in the effort to not only reduce pain but also to reduce neovascularization and recurrence. Currently, efforts are being made to reduce inflammation and trauma in surgery by employing vein-sparing techniques. Differences in GSV anatomy and patterns of reflux indicate that treatment should be individualized according to the specific characteristics of each patient [19]. Such practices are likely to improve the efficiency of surgical treatment while minimizing unnecessary trauma. Techniques such as endovenous ambulatory selective varicose vein ablation under local anesthesia (eASVAL), which eliminates varicosities but preserves the GSV, have shown good results with respect to clinical efficacy and durable elimination of reflux [20]. Other surgical methods that preserve the saphenofemoral confluence have also been shown to be effective in terms of eliminating reflux $(98.2 \%)$, reducing Clinical-EtiologicalAnatomical-Pathophysiological Classification (CEAP) clinical class (83.9\%), symptom improvement (91.3\%), and aesthetic benefit (95.5\%) [21]. These assessments were performed after a median follow-up of 27.3 months in 151 patients; longer-term results are unknown, but may be positive as well. Additionally, a minimally invasive technique of hemodynamic correction (Ambulatory Conservative Hemodynamic Treatment of Venous Insufficiency, identified by the acronym CHIVA from the French Conservatrice Hémodynamique de l'Insuffisance Veineuse en Ambulatoire), in which the GSV is maintained and reflux points with the change of venous compartments are eliminated, has also shown promise. In a long-term clinical trial comparing CHIVA to conventional stripping, overall recurrence was significantly lower with CHIVA ( $18 \%$ vs $35 \%$; $P<0.038$ ) over a mean follow-up of 10 years [22]. However, this study also showed that the location of recurrence associated with either technique tended to present where the greatest amount of surgical trauma occurred. These results show that techniques that minimize trauma can be beneficial with respect to recurrence, but also provide another example where localized trauma and inflammation are tightly associated with varicose vein recurrence. 
In another approach to reducing perioperative pain and inflammation during ambulatory phlebectomy, diluting the tumescent anesthetic mepivacaine in isotonic sodium bicarbonate, which has been shown to reduce subcutaneous pain associated with infiltration anesthesia, resulted in significantly less pain compared to mepivacaine-saline controls [23]. Long-term follow-up of these patients will be necessary to determine whether this approach can influence varicose vein recurrence rates.

\section{CONCLUSIONS}

The treatment of reflux (not disease) remains the mainstream paradigm in the management of patients with varicose veins. However, the long-term results of EVA and surgical approaches are not different with respect to varicose vein recurrence, and this recurrence appears to be a manifestation of disease progression. Since inflammation is one of the key mechanisms of CVD development and progression, efforts to minimize inflammation and angiogenic potential in endovenous and surgical procedures are worthwhile. As techniques continue to be refined, surgery remains a valid option, especially if perioperative trauma can be minimized. Finally, medical treatment with VAD such as MPFF, which has proven clinical benefits in patients with CVD, can be used before and after EVA or surgery to minimize inflammation, pain, hemorrhage, and reduce CVD symptoms. All of these aspects of invasive vein treatment may improve long-term results and warrant further clinical attention.

\section{ACKNOWLEDGEMENTS}

Funding. This supplement has been sponsored by Servier. The Rapid Service Fee and Open Access fees were funded by Servier.

Medical Writing. Medical writing services were provided by Dr. Kurt Liittschwager (4Clinics, France) and were funded by Servier.
Authorship. Dr. Fedor Lurie meets the International Committee of Medical Journal Editors (ICMJE) criteria for authorship for this article, takes responsibility for the integrity of the work as a whole, and has approved this version for publication.

Prior Presentation. This article and all of the articles in this supplement are based on the international satellite symposium at the European Venous Forum (June 2019, Zurich, Switzerland).

Disclosures. Dr. Fedor Lurie has received Servier support for travel and preparation of the manuscript.

Compliance with Ethics Guidelines. This article is based on previously conducted studies and does not contain any studies with human participants or animals performed by the author.

Open Access. This article is licensed under a Creative Commons Attribution-NonCommercial 4.0 International License, which permits any non-commercial use, sharing, adaptation, distribution and reproduction in any medium or format, as long as you give appropriate credit to the original author(s) and the source, provide a link to the Creative Commons licence, and indicate if changes were made. The images or other third party material in this article are included in the article's Creative Commons licence, unless indicated otherwise in a credit line to the material. If material is not included in the article's Creative Commons licence and your intended use is not permitted by statutory regulation or exceeds the permitted use, you will need to obtain permission directly from the copyright holder. To view a copy of this licence, visit http:// creativecommons.org/licenses/by-nc/4.0/.

\section{REFERENCES}

1. Kheirelseid EAH, Crowe G, Sehgal R, et al. Systematic review and meta-analysis of randomized controlled trials evaluating long-term outcomes of 
endovenous management of lower extremity varicose veins. J Vasc Surg Venous Lymphat Disord. 2018;6(2):256-70.

2. O'Donnell TF, Balk EM, Dermody M, Tangney E, Iafrati MD. Recurrence of varicose veins after endovenous ablation of the great saphenous vein in randomized trials. J Vasc Surg Venous Lymphat Disord. 2016;4(1):97-105.

3. Cirocchi R, Henry BM, Rambotti M, et al. Systematic review and meta-analysis of the anatomic variants of the saphenofemoral junction. J Vasc Surg Venous Lymphat Disord. 2019;7(1):128-138. e7.

4. Neser RA, Caffaro RA. Invagination stripping with ultrasound-guided perivenous tumescence: an original method of great saphenous vein stripping. Dermatol Surg. 2011;37(3):349-52.

5. Proebstle TM, Paepcke U, Weisel G, Gass S, Weber L. High ligation and stripping of the long saphenous vein using the tumescent technique for local anesthesia. Dermatol Surg. 1998;24(1):149-53.

6. Sadick NS, Schanzer H. Combined high ligation and stab avulsion for varicose veins in an outpatient setting. Dermatol Surg. 1998;24(4):475-9.

7. Lurie F, Creton D, Eklof B, et al. Prospective randomized study of endovenous radiofrequency obliteration (closure procedure) versus ligation and stripping in a selected patient population (EVOLVeS Study). J Vasc Surg. 2003;38(2):207-14.

8. Rasmussen L, Lawaetz M, Serup J, et al. Randomized clinical trial comparing endovenous laser ablation, radiofrequency ablation, foam sclerotherapy, and surgical stripping for great saphenous varicose veins with 3-year follow-up. J Vasc Surg Venous Lymphat Disord. 2013;1(4):349-56.

9. Nandhra S, El-sheikha J, Carradice D, et al. A randomized clinical trial of endovenous laser ablation versus conventional surgery for small saphenous varicose veins. J Vasc Surg. 2015;61(3):741-6.

10. Cappelli M, Molino-Lova R, Giangrandi I, Ermini S, Gianesini S. Ligation of the saphenofemoral junction tributaries as risk factor for groin recurrence. J Vasc Surg Venous Lymphat Disord. 2018;6(2): 224-9.

11. Raffetto JD, Mannello F. Pathophysiology of chronic venous disease. Int Angiol. 2014;33(3): 212-21.

12. Mansilha A, Sousa J. Pathophysiological mechanisms of chronic venous disease and implications for venoactive drug therapy. Int J Mol Sci. 2018. https://doi.org/10.3390/ijms19061669.

13. Taengsakul N, Saikaew $\mathrm{T}$, Chaiaroon $\mathrm{N}$, et al. Inflammatory responses in varicose veins surgery: conventional venous stripping and endovenous radiofrequency ablation (EV-RFA). J Vasc Endovasc Ther. 2019;4(1):9.

14. Veverkova L, Kalac J, Jedlicka V, Wechsler J. Analysis of surgical procedures on the vena saphena magna in the Czech Republic and an effect of Detralex during its stripping. Rozhl Chir. 2005;84(8):410-2, 4-6.

15. Veverková L, Kalač J, Jedlička V, Wechsler J. Analysis of the various procedures used in great saphenous vein surgery in the Czech Republic and benefit of Daflon $500 \mathrm{mg}$ to postoperative symptoms. Phlebolymphology. 2006;13(4):193-9.

16. Pokrovsky AV, Saveljev VS, Kirienko AI, et al. Surgical correction of varicose vein disease under micronized diosmin protection (results of the Russian multicenter controlled trial DEFANS). Angiol Sosud Khir. 2007;13(2):47-55.

17. Saveljev VS, Pokrovsky AV, Kirienko AI, Bogachev VY, Zolotukhin IA, Sapelkin SV. Stripping of the great saphenous vein under micronized purified flavonoid fraction (MPFF) protection (results of the Russian multicenter controlled trial DEFANCE). Phlebolymphology. 2008;15(2):45-51.

18. Ashpitel HF, Dabbs EB, Salguero FJ, Nemchand JL, La Ragione RM, Whiteley MS. Histopathologic differences in the endovenous laser ablation between jacketed and radial fibers, in an ex vivo dominant extrafascial tributary of the great saphenous vein in an in vitro model, using histology and immunohistochemistry. J Vasc Surg Venous Lymphat Disord. $2019 ; 7(2): 234-45$.

19. Chastanet S, Pittaluga P. Patterns of reflux in the great saphenous vein system. Phlebology. 2013;28(Suppl 1):39-46.

20. Atasoy MM, Oguzkurt L. The endovenous ASVAL method: principles and preliminary results. Diagn Interv Radiol. 2016;22(1):59-64.

21. Pittaluga P, Chastanet S, Guex JJ. Great saphenous vein stripping with preservation of saphenofemoral confluence: hemodynamic and clinical results. J Vasc Surg. 2008;47(6):1300-4 (discussion 4-5).

22. Carandina S, Mari C, De Palma M, et al. Varicose vein stripping vs haemodynamic correction 
(CHIVA): a long term randomised trial. Eur J Vasc Endovasc Surg. 2008;35(2):230-7.

23. Moro L, Serino FM, Ricci S, Abbruzzese G, Antonelli-Incalzi R. Dilution of a mepivacaine- adrenaline solution in isotonic sodium bicarbonate for reducing subcutaneous infiltration pain in ambulatory phlebectomy procedures: a randomized, double-blind, controlled trial. J Am Acad Dermatol. 2014;71(5):960-3. 